\title{
Extremely Rare Syndrome: Pseudotrisomy 13
}

\author{
Mehmet Davutoglu ${ }^{\mathrm{a}, \mathrm{d}}$, Ali Murat Kalender ${ }^{\mathrm{b}}$, Fuat Ozkan ${ }^{\mathrm{c}}$, Esra Bebek ${ }^{\mathrm{a}}$, \\ Muhammed Udurgucu ${ }^{a}$, Tahir Dalkiran ${ }^{a}$
}

\begin{abstract}
Pseudotrisomy 13 syndrome is extremely rare, characterized by holoprosoncephaly, microcephaly, anophthalmy, single athresic nasi, cleft palate and extremity anomalies such as polydactyly and olygodactyly with a normal karyotype. We have report a newborn pseudotrisomy 13 patient, a normal karyotype 46 XY. Clinical and laboratory findings were diagnosed with pseudotrisomy 13 syndrome. The case died after 12 days due to cardio-respiratory failure.
\end{abstract}

Keywords: Pseudotrisomy 13 syndrome; Newborn; Olygodactyly

\section{Introduction}

Pseudotrisomy 13 syndrome is extremely rare, autosomal recessive transmitted chromosomal disorder characterized by abnormal frontal cerebral development (holoprosoncephaly), microcephaly, anophthalmy, middle facial defects such as single athresic nasi, cleft palate and extremity anomalies. It is differentiated from trisomy 13 by normal karyotype.

We present a patient with phenotypic features highly suggestive of trisomy 13 with a normal karyotype.

Manuscript accepted for publication February 14, 2012

\footnotetext{
${ }^{a}$ Department of Pediatrics, Faculty of Medicine, Kahramanmaras Sutcu Imam University, Turkey

${ }^{b}$ Department of Orthopaedics Traumathology, Faculty of Medicine, Kahramanmaras Sutcu Imam University, Turkey

${ }^{\mathrm{c}}$ Department of Diagnostic Radiology, Faculty of Medicine,

Kahramanmaras Sutcu Imam University, Turkey

${ }^{\mathrm{d}}$ Corresponding author: Mehmet Davutoglu, Kahramanmaras Sutcu

Imam University, Faculty of Medicine, Department of Pediatrics

(TR-46050) Kahramanmaras, Turkey.

Email: drmdavutoglu@hotmail.com
}

\section{Case Report}

This male was born on term, by C-section, with a body weight of $2160 \mathrm{~g}$ ( $<3 \mathrm{rd}$ centile) length of $47 \mathrm{~cm}$ ( $3-10$ th centile) and head circumference of $27 \mathrm{~cm}(<3$ th centile). The patient was immediately transferred to our neonatal intensive care unit because of facial dysmorphism and poor general condition (Fig. 1). He was the first child of non-consanguineous parents and the family history was unremarkable. The father was 30 and the mother 28 years old. Their karyotypes were normal. Clinical examination revealed microcephaly, a flat rudimentary nose with a single nasal cavity, hypotelorism, anophthalmia, cleft palate, olygodactyly and a short neck (Fig. 1, 2).

Cerebral ultrasonography revealed a lobar holoprosencephaly with an absence of midline structures of the brain. Echocardiogram and renal ultrasound were normal. Chromosome analysis from peripheral blood revealed a normal karyotype, 46 XY. Clinical and laboratory findings pointed out pseudotrisomy 13 syndrome. The case died at 12 days owing to cardio-respiratory failure.

\section{Discussion}

Pseudotrisomy 13 syndrome was first suggested in 1991 by

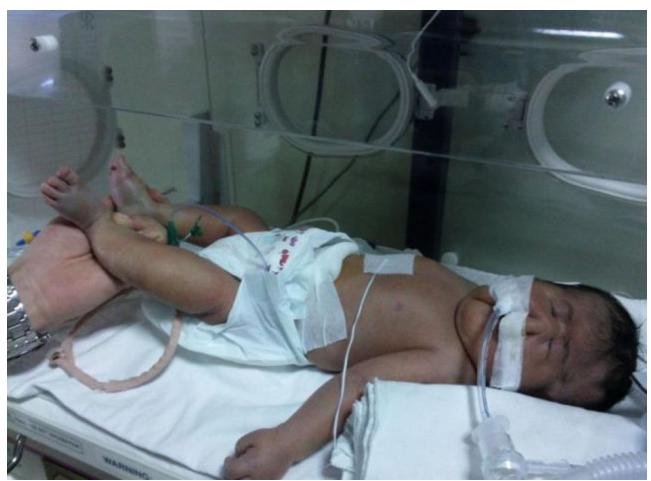

Figure 1. The pseudotrisomy 13 syndrome was seen appearance of our case. 


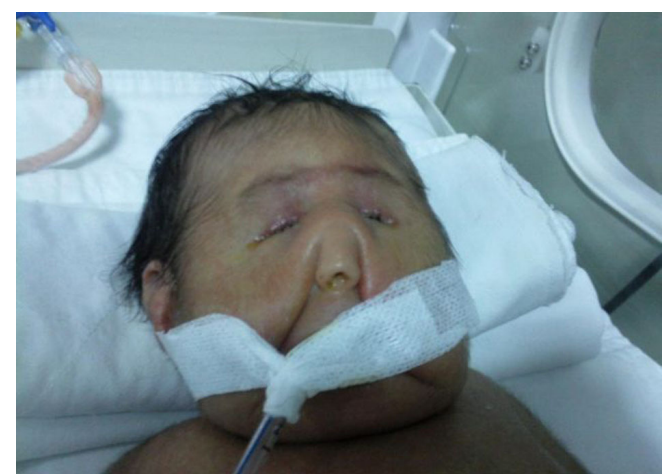

Figure 2. The patient was seen microcephaly, anophthalmia, hypotelorism, flat rudimentary nose with single nostril and short neck.

Cohen et al. It is defined in chromosomally normal patients with holoprosencephaly and associated features were suggestive of trisomy 13 such as microcephaly, hypotelorism, cleft palate, anophthalmia $[1,2]$. An autosomal recessive pattern of inheritance for this situation seems most likely, but a gene has not yet been mapped.

Haloprosencephaly and polydactyly are major criteria in this anomaly but polydactyly may not coexist. The diagnostic findings are normal chromosomal pattern associated with haloprosencephaly and polydactyly but sometimes other characteristic anomalies without polydactyl [3]. The olygodactily was present instead of polydactyly in our patient with other characteristic diagnostic findings. The autosomal recessive transmission is estimated in this patient which is noticeable point in usual relative marriages common countries.

The Meckel syndrome, Pallister-Hall syndrome, trisomy 13, hydroletalus syndrome, and Smith-Lemli-Opitz syndrome must be excluded in differential diagnosis [4]. These syndromes were differentiated by specific characteristic findings. The microcephaly, anophthalmy, single athresic nasal cavity, short neck, cleft palate, holoprosencephaly, patent foramen ovale and oligodactly were observed in our patient. These finding are evaluated as trisomy 13. However it is diagnosed as pseudotrisomy 13 finally because of the normal karyotype [5-7].

The diagnosis of pseudotrisomy 13 is an important one in view of the implications for genetic counseling. The family is referred to genetic consultation for further pregnancies.

\section{References}

1. Bachman H, Clark RD, Salahi W. Holoprosencephaly and polydactyly: a possible expression of the hydrolethalus syndrome. Journal of medical genetics. 1990;27(1):50-52.

2. Cohen MM, Jr., Gorlin RJ. Pseudo-trisomy 13 syndrome. American journal of medical genetics. 1991;39(3):332335; discussion 336-337.

3. Lurie IW, Wulfsberg EA. "Holoprosencephaly-polydactyly" (pseudotrisomy 13) syndrome: expansion of the phenotypic spectrum. American journal of medical genetics. 1993;47(3):405-409.

4. Verloes A, Ayme S, Gambarelli D, Gonzales M, Le Merrer M, Mulliez N, Philip N, et al. Holoprosencephaly-polydactyly ('pseudotrisomy 13') syndrome: a syndrome with features of hydrolethalus and Smith-Lemli-Opitz syndromes. A collaborative multicentre study. Journal of medical genetics. 1991;28(5):297-303.

5. Tolmie JL. Down syndrome and other autosomal trisomies. In: Rimoin DL, Connor JM, Pyeritz RE, Korf BR (eds). Principles and Practice of Medical Genetics (4th ed) Vol 1. China: Churchill Livingstone; 2002: 11291183 .

6. Utine GE, Alanay Y, Aktas D, Talim B, Kale G, Tuncbilek E. Pseudo-trisomy 13 in a fetus: further support for autosomal recessive inheritance. The Turkish journal of pediatrics. 2008;50(3):287-290.

7. Schulz S, Gerloff C, Kalinski T, Mawrin C, Kanakis D, Haas D, Hahn H, et al. Pseudotrisomy 13: clinical findings and genetic implications. Fetal diagnosis and therapy. 2005;20(6):501-503. 